\title{
BMJ Open Association between COX-2 gene polymorphisms and risk of hepatocellular carcinoma development: a meta-analysis
}

\author{
Si-Cong Lu, ${ }^{1}$ Jian-Hong Zhong, ${ }^{2}$ Jun-Tao Tan, ${ }^{2}$ Hua-Lin Tang, ${ }^{2}$ Xiao-Guang Liu, ${ }^{1}$ \\ Bang-De Xiang, ${ }^{2}$ Le-Qun Li, ${ }^{2}$ Tao Peng ${ }^{1}$
}

To cite: Lu S-C, Zhong J-H, Tan J-T, et al. Association between COX-2 gene polymorphisms and risk of hepatocellular carcinoma development: a metaanalysis. BMJ Open 2015;5 e008263. doi:10.1136/ bmjopen-2015-008263

- Prepublication history for this paper is available online. To view these files please visit the journal online (http://dx.doi.org/10.1136/ bmjopen-2015-008263).

Received 25 March 2015 Revised 5 August 2015 Accepted 12 August 2015



\footnotetext{
${ }^{1}$ Hepatobiliary Surgery Department, First Affiliated Hospital of Guangxi Medical University, Nanning, PR China

${ }^{2}$ Hepatobiliary Surgery Department, Affiliated Tumor Hospital of Guangxi Medical University, Nanning, PR China
}

Correspondence to Professor Tao Peng; 3041375003@qq.com

\section{ABSTRACT}

Objective: To investigate the association between cyclo-oxygenase-2 (COX-2) polymorphism and the risk of hepatocellular carcinoma (HCC) development.

Design: Systematic review and meta-analysis of COX2 polymorphism and risk of $\mathrm{HCC}$ development among people with or without HCC.

Data sources: EMBASE, PubMed, Public Library of Science, SCOPUS, Web of Knowledge and Chinese National Knowledge Infrastructure were searched for all clinical and experimental case-control studies of COX2 polymorphism and HCC risk. Studies published up to March 2015 were included.

Review method: Ten studies were included for data extraction, which were mainly from Asian countries. Results: 2538 people with HCC and 3714 without HCC were found to satisfy the inclusion criteria and included in the review. The associations of specific genotypes in the eight polymorphic variants of COX-2 and the risk of HCC development were analysed. GG genotype at the A-1195G polymorphism may be associated with a reduced risk of HCC development: the OR across all studies was $0.87(95 \% \mathrm{Cl} 0.75$ to 1.02) for the $G$ allele versus the $A$ allele, 0.72 ( 0.53 to 0.97 ) for $G G$ versus $A A, 0.72$ ( 0.57 to 0.92$)$ for $G G$ versus $G A+A A$ and 1.05 ( 0.77 to 1.44 ) for AA versus $G A+G G$. Similar results were found when the metaanalysis was repeated separately for the Chinese subgroup. However, more reliable data are needed to demonstrate associations between variants in G-765C, T+8473C, A-1290G, G-899C and introns 1, 5 and 6 polymorphisms and the risk of HCC development. Conclusions: Only the COX-2 A-1195G gene polymorphism may be associated with a decreased risk of HCC development. These conclusions should be verified in further studies.

\section{INTRODUCTION}

Hepatocellular carcinoma (HCC) is a significant cause of cancer morbidity and mortality worldwide. The estimated incidence of new HCC cases each year is more than 0.5

\section{Strengths and limitations of this study}

- Eight polymorphic variants of cyclo-oxygenase-2 gene were studied.

- The study was limited by a lack of gene-gene and gene-environment interaction data.

- This study was also limited by the small sample size in some polymorphic variants.

million. ${ }^{1}$ China is one of the regions with highest incidence of HCC ( $>20$ per 100000 people), which accounts for more than $50 \%$ of the total number of cases. $^{2}{ }^{3}$ Epidemiologically, HCC is strongly associated with hepatitis B or $\mathrm{C}$ virus infection, alcohol consumption and metabolic disease. However, not all people with these factors appear to have the same risk of developing HCC. HCC is a multifactorial disease and many studies have shown that gene polymorphisms may also contribute to the risk of hepatocarcinogenesis. ${ }^{45}$ Patients with HCC exhibit a high degree of genetic heterogeneity.

Cyclo-oxygenase-2 (COX-2, also known as prostaglandin endoperoxide synthases or prostaglandin $\mathrm{H}$ synthases), is an inducible enzyme that converts arachidonic acid to prostaglandins, which are potent mediators of inflammation. COX-2 is not normally present in most tissue cells. It is induced in response to inflammatory cytokines, mitogens, angiogenic growth factors and tumour promoters. ${ }^{6} 7$ Increased COX-2 expression has been associated with the early stages of hepatocarcinogenesis. ${ }^{8} 9$ However, the association of COX-2 genotypes polymorphism with the risk of HCC development has not been established.

Recently, a number of studies ${ }^{10-19}$ have examined whether an association exists between COX-2 polymorphism and the risk 
of developing HCC. These studies have reached different conclusions, with some suggesting a significant association and others no association. Since individual casecontrol studies may fail to detect a complicated genetic relationship because of small sample size, this review aims to comprehensively assess the literature examining a possible link between the COX-2 polymorphism and the risk of HCC development.

\section{METHODS}

\section{Literature search strategy}

All clinical and experimental case-control studies of COX-2 polymorphism and the risk of developing HCC published up to 31March 2015 were identified through systematic searches in EMBASE, PubMed, Public Library of Science (http://www.plos.org), SCOPUS, Web of Knowledge and Chinese National Knowledge Infrastructure. A large number of papers have been published recently by the Public Library of Science and so we also searched this database. No language restriction was imposed. The following search terms were used to identify studies: cyclo-oxygenase-2 or COX-2, gene or polymorphism or variation or genotype or genetic or mutation, "hepatocellular carcinoma" or "liver cancer" or HCC. Detailed database search strategies of EMBASE are shown in table 1. We also searched the Catalog of Published Genome-Wide Association Studies (http://www.genome. gov/gwastudies) of the US National Human Genome Research Institute. Reference lists of these articles and relevant literature from review articles were also examined to identify additional relevant publications.

\section{Inclusion criteria}

Only full-length research studies satisfying the following criteria were included in this review: (a) they assessed the association between COX-2 polymorphism and the risk of HCC development; (b) they used a case-control or cohort design in which cases were patients with HCC and controls were healthy people, or people with chronic hepatitis B or C, or with cirrhosis; (c) they focused on human beings; (d) they provided sufficient published data to allow estimation of an OR with a $95 \%$ CI. In the case of multiple studies apparently based on the same case or control population, we included only the study with the largest number of participants. Conference abstracts or other summaries were not included. If the data on genotype frequency in the study were incomplete, we tried to contact the authors to collect these data. ${ }^{20}$

\section{Data extraction}

Two authors (S-CL, J-TT) independently searched the literature and identified eligible articles based on our inclusion criteria. These two authors also independently extracted the following data from included studies: first author's family name, year of publication, genotyping methods, source of controls (population-based and hospital-based), numbers and genotypes of cases and controls and Hardy-Weinberg equilibrium (HWE) of controls. Extracted data were compared and discrepancies were resolved by discussion with a third author ( $\mathrm{J}-\mathrm{HZ})$.

\section{Statistical methods and bias testing}

As described previously, ${ }^{20}{ }^{21}$ the unadjusted OR with 95\% CI was used to assess the strength of the association between the COX-2 polymorphism and HCC susceptibility based on the genotype frequencies in cases and controls. The meta-analysis examined the association between different genotypes at different loci of COX-2 and HCC risk by comparing the alleles, comparing homozygous genotypes and applying recessive and dominant genetic models.

\begin{tabular}{|c|c|c|}
\hline Database & $\begin{array}{l}\text { Time span of } \\
\text { search }\end{array}$ & Search strategy \\
\hline EMBASE (Ovid SP) & $\begin{array}{l}1990 \text { to } \\
\text { March } 2015\end{array}$ & $\begin{array}{l}\text { 1. exp CYCLOOXYGENASE-2 } \\
\text { 2. (cyclo-oxygenase-2* or COX-2* } 2^{*} \text {. mp.[mp=title, abstract, subject headings, } \\
\text { heading word, original title, drug trade name, drug manufacturer] } \\
\text { 3. } 1 \text { or } 2 \\
\text { 4. (gene }{ }^{*} \text { or polymorphism }{ }^{*} \text { or variation }{ }^{*} \text { or genotype }{ }^{*} \text { or genetic }{ }^{*} \text { or mutation }{ }^{*} \text { ).mp. } \\
\text { [mp=title, abstract, subject headings, heading word, original title, drug trade name, } \\
\text { drug manufacturer] } \\
\text { 5. exp liver cell carcinoma/ } \\
\text { 6. exp liver tumour/ } \\
\text { 7. (((liver or hepatic or hepatocellular or hepato-cellular) and (carcinom* or cancer* } \\
\text { or neoplasm* or malign* or tumo*)) or HCC).mp.[mp=title, abstract, subject } \\
\text { headings, heading word, drug trade name, original title, device manufacturer, drug } \\
\text { manufacturer] } \\
\text { 8. } 5 \text { or } 6 \text { or } 7 \\
\text { 9. } 3 \text { and } 4 \text { and } 8\end{array}$ \\
\hline
\end{tabular}

HCC, hepatocellular carcinoma. 
A Mantel-Haenszel estimate was used to give a pooled OR using a fixed-effect model, while a DerSimonianLaird estimate used a random-effect model. The significance of OR was assessed using the $\mathrm{Z}$ test, and $\mathrm{p}<0.05$ was considered statistically significant. $\mathrm{I}^{2}$ was used to estimate total variation across studies due to heterogeneity in percentage. ${ }^{22} 23$ A percentage of $<25 \%$ was considered as a low level of heterogeneity, $25-50 \%$ as a moderate level of heterogeneity and $>50 \%$ as a high level of heterogeneity. $\mathrm{I}^{2}>50 \%$ could suggest heterogeneity and suggest using a random-effect estimate. ${ }^{22} 23$ Otherwise, the fixed-effect model was used to calculate pooled ORs. HWE in the control group was assessed using the $\chi^{2}$ goodness-of-fit test, with $\mathrm{p}<0.05$ considered significant. As far as possible, the meta-analysis was performed according to the PRISMA guidelines. ${ }^{24}$

As described previously, ${ }^{20}{ }^{21}$ to detect associations that might be masked in the overall sample, we performed subgroup analyses based on ethnicity. Meta-regression was performed to examine the effect of ethnicity to compare results from the meta-analyses. To assess the reliability of the outcomes in the meta-analysis, a sensitivity analysis was performed by excluding one study at a time.

Publication bias was assessed by visual inspection of Begg's funnel plots. An asymmetric plot suggested possible publication bias, in which case Egger's test was used. ${ }^{25}$ All statistical tests for this meta-analysis were performed using Stata V.11.0 (Stata-Corp, College Station, USA) and RevMan V.5.3 (Cochrane Collaboration).

\section{RESULTS}

\section{Description of studies}

Several research databases were searched to identify studies assessing the possible association between the polymorphism in the COX-2 gene and the risk of developing HCC. A total of 562 studies were identified, none of which was a genome-wide association study. This list was reduced to 22 after removing duplicates and screening based on the title and abstract review. These articles were read in full and eight studies were removed because they did not include a control group, while another four studies were removed because overlapping patients were analysed or the data were incomplete. No study which was published in a language other than in Chinese or in English was excluded. Finally, 10 studies were included in the analysis (figure 1). ${ }^{10-19}$ Four were published in Chinese ${ }^{12141517}$ and the other six studies were published in English. ${ }^{10} \quad 11 \quad 13 \quad 16 \quad 18 \quad 19$ The main characteristics of the included studies are shown in tables 2-4. All the studies reported that the cases and controls were matched for age and gender.

The studies included 2538 people with HCC and 3714 people without HCG. The A-1195G polymorphism in the COX-2 gene and risk of HCC development was reported by eight studies ${ }^{10-17}$ (table 2), G-765C in six studies $^{10} \quad 1113 \quad 14 \quad 17 \quad 18$ (table 3 ) and $\mathrm{T}+8473 \mathrm{C}$ in three studies (table 4$).^{10-12}$

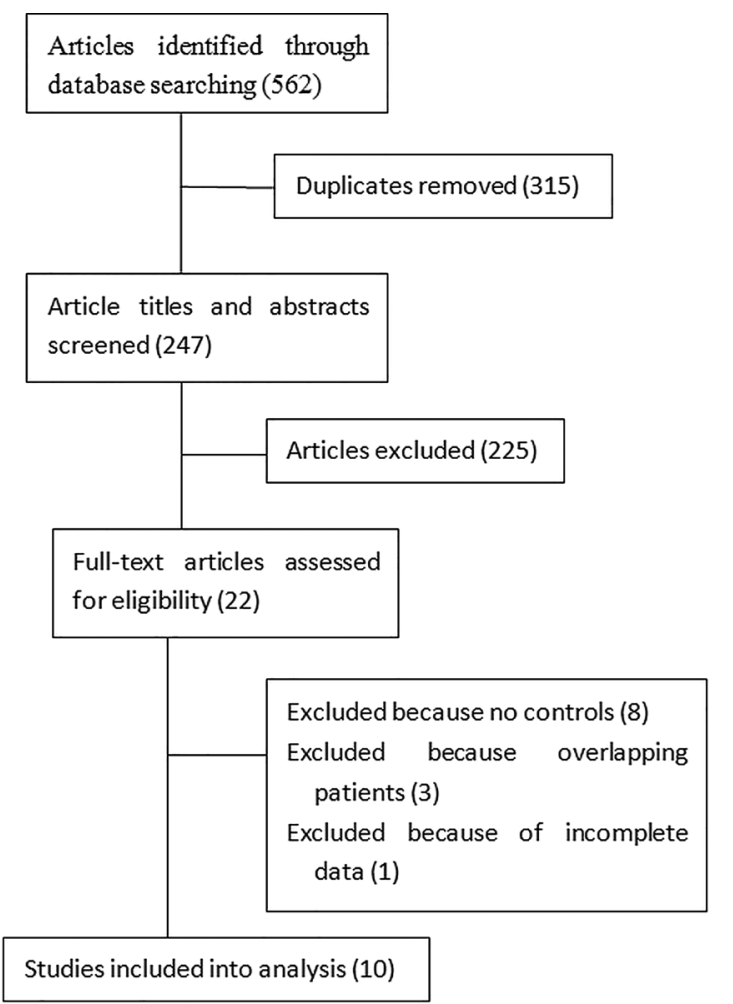

Figure 1 Flow chart of study selection.

\section{Quantitative data synthesis \\ A-1195G}

Although the polymorphism in the allelic contrast model only slightly affects HCC development risk $(\mathrm{OR}=0.87,95 \%$ CI 0.75 to $1.02, \mathrm{p}=0.09)$, the GG genotype was significantly associated with a reduced risk across the genetic models tested: the OR across all studies was 0.72 (95\% CI 0.53 to 0.97 ) for the GG versus AA and 0.72 (95\% CI 0.57 to 0.92 ) for GG versus GA +AA (figure 2). However, the AA genotype was not associated with higher or lower HCC development risk: the OR across all studies was 1.05 (95\% CI 0.77 to 1.44 ) for AA versus GA+GG (table 5). The results after deleting each study were similar to those obtained across all studies. We loosely classified the study population as Chinese and non-Chinese based on the ethnicity of the participants. Meta-analyses of subgroups found that Chinese population has the same phenomena as the total population. However, the A-1195G polymorphism in the COX-2 gene was not associated with either increased or reduced risk of HCC development in the non-Chinese population (table 5). Meta-regression also supported our results (table 6).

\section{G-765C}

For the COX-2 G-765C polymorphism, no significant association was seen in any of the six studies $(\mathrm{C}$ allele vs $\mathrm{G}$ allele: $\mathrm{OR}=1.32,95 \%$ CI 0.76 to 2.30 ; $\mathrm{CC}$ vs $\mathrm{GC}+\mathrm{GG}$ : $\mathrm{OR}=0.88,95 \%$ CI 0.16 to 4.75 ; $\mathrm{CC}$ vs GG: $\mathrm{OR}=0.93,95 \%$ CI 0.16 to 5.35 ; GG vs $\mathrm{CC}+\mathrm{GC}$ : $\mathrm{OR}=0.48$, $95 \%$ CI 0.14 to 1.59). Since the two non-Chinese studies ${ }^{10} 13$ had a 
Table 2 Main characteristics of studies of the cyclo-oxygenase-2 A-1195G polymorphism and the risk of hepatocellular carcinoma

\begin{tabular}{|c|c|c|c|c|c|c|c|c|c|c|c|}
\hline \multirow[b]{2}{*}{ Study } & \multirow[b]{2}{*}{ Country } & \multirow{2}{*}{$\begin{array}{l}\text { Source of } \\
\text { control }\end{array}$} & \multirow{2}{*}{$\begin{array}{l}\text { Genotyping } \\
\text { method }\end{array}$} & \multirow[b]{2}{*}{$\mathbf{P}_{\mathrm{HWE}}$} & \multirow{2}{*}{$\begin{array}{l}\text { Cases/ } \\
\text { controls }\end{array}$} & \multicolumn{3}{|c|}{ No. of cases } & \multicolumn{3}{|c|}{ No. of controls } \\
\hline & & & & & & GG & GA & AA & GG & GA & AA \\
\hline$\overline{A k k i z ~ e t ~ a l^{10}}$ & Turkey & $\mathrm{HB}$ & PCR-RFLP & 1 & $129 / 129$ & 2 & 36 & 91 & 2 & 32 & \\
\hline Chang et $a l^{11}$ & Taiwan & PB & PCR-RFLP & 0.57 & $298 / 298$ & 70 & 144 & 84 & 72 & 145 & 81 \\
\hline Fan et $a^{12}$ & China & $\mathrm{HB}$ & $\begin{array}{l}\text { TaqMan genotyping } \\
\text { platform }\end{array}$ & 0.52 & $780 / 780$ & 204 & 390 & 186 & 205 & 381 & 194 \\
\hline Gharib et $a l^{13}$ & Egyp & PB & PCR-RFLP & 0.86 & & 17 & 60 & 43 & 31 & 66 & \\
\hline $\mathrm{Li}$ and Meng ${ }^{14}$ & China & PB & PCR-RFLP & 0.15 & $178 / 196$ & 31 & 88 & 59 & 54 & 88 & 5 \\
\hline Liu et $a l^{15}$ & China & $\mathrm{HB}$ and $\mathrm{PB}$ & PCR-RFLP & 0.56 & $210 / 420$ & 31 & 110 & 69 & 101 & 216 & 103 \\
\hline Mohamed et $a l^{16}$ & Egypt & $\mathrm{HB}$ and $\mathrm{PB}$ & PCR-RFLP & $<0.001$ & $75 / 125$ & 12 & 49 & 14 & 40 & 22 & \\
\hline Xu et al $1^{17}$ & China & PB & PCR-RFLP & 0.14 & $270 / 540$ & 52 & 125 & 93 & 119 & 287 & 134 \\
\hline
\end{tabular}

HB, hospital-based; PB, population-based; PCR-RFLP, PCR-restriction fragment length polymorphism; $P_{\text {HWE, Hardy-Weinberg equilibrium of }}$ controls.

small sample size and the GG genotype was absent in three studies, ${ }^{11} 14{ }^{17}$ subgroup analyses were not performed (table 5).

\section{$\mathrm{T}+8473 \mathrm{C}$}

For the COX-2 $\mathrm{T}+8473 \mathrm{C}$ polymorphism, no significant association was seen in all the three studies $(\mathrm{C}$ allele vs T allele: $\mathrm{OR}=0.99,95 \%$ CI 0.86 to 1.14 ; $\mathrm{CC}$ vs $\mathrm{CT}+\mathrm{TT}$ : $\mathrm{OR}=1.31,95 \%$ CI 0.83 to 2.07 ; $\mathrm{CC}$ vs $\mathrm{TT}$ : $\mathrm{OR}=1.25,95 \%$ CI 0.78 to 1.98 ; TT vs $\mathrm{CT}+\mathrm{CC}$ : $\mathrm{OR}=1.05,95 \%$ CI 0.89 to 1.24) (table 5).

\section{Other loci}

The study by Chang et $a l^{11}$ also reported three loci polymorphisms in the COX-2 gene: intron 1, intron 5 and intron 6. This study showed that, for each of the six genotypes, no differences in distribution between the HCC and control groups were found. The locus polymorphism of A-1290G was reported by one study with 270 cases and 540 healthy controls. ${ }^{17}$ This study found no significant association between the COX-2 A-1290G polymorphism and risk of HCC. The locus polymorphism of C-899G in the COX-2 gene was also reported by one study with 300 patients with chronic hepatitis $\mathrm{B}, 300$ patients with liver cirrhosis, 300 patients with HCC and 300 healthy controls. ${ }^{19}$ This study found that the
COX-2-899C genotype may increase the susceptibility of individuals to HCC.

Publication bias and small-study bias

Begg's funnel plots were prepared for the eight studies to assess publication bias for studies of the A-1195G polymorphism of COX-2 and HCG risk. The shape of the funnel plots appeared to be symmetrical for allele contrast, homozygous comparison and recessive and dominant genetic models, suggesting the absence of publication bias. Moreover, Egger's test also suggested no publication bias (table 6 ).

\section{DISCUSSION}

Some studies reported an association between the COX-2 gene polymorphism and the risk of HCC development, while others found no such association. The most likely reason for the inconsistencies among these studies is the small sample size. To help resolve these conflicting results using a larger sample size, we conducted a systematic review of published studies. In this review, we included 10 studies investigating the association of eight polymorphic variants of COX-2 and the HCC development risk. We found that the GG genotype of A-1195G in the COX-2 gene was associated with a decreased risk of HCC development, especially in a

Table 3 Main characteristics of studies of cyclo-oxygenase-2 G-765C polymorphism and the risk of hepatocellular carcinoma

\begin{tabular}{|c|c|c|c|c|c|c|c|c|c|c|c|}
\hline \multirow[b]{2}{*}{ Study } & \multirow[b]{2}{*}{ Country } & \multirow{2}{*}{$\begin{array}{l}\text { Source of } \\
\text { control }\end{array}$} & \multirow{2}{*}{$\begin{array}{l}\text { Genotyping } \\
\text { method }\end{array}$} & \multirow[b]{2}{*}{$\mathbf{P}_{\text {HWE }}$} & \multirow{2}{*}{$\begin{array}{l}\text { Cases/ } \\
\text { controls }\end{array}$} & \multicolumn{3}{|c|}{ No. of cases } & \multicolumn{3}{|c|}{ No. of controls } \\
\hline & & & & & & $\overline{\mathbf{G G}}$ & GA & $\overline{A A}$ & $\overline{\text { GG }}$ & GA & AA \\
\hline Akkiz et al ${ }^{10}$ & Turkey & $\mathrm{HB}$ & PCR-RFLP & 0.009 & $129 / 129$ & 4 & 46 & 79 & 15 & 39 & 75 \\
\hline Chang et al ${ }^{11}$ & Taiwan & PB & PCR-RFLP & 0.13 & $298 / 298$ & 0 & 36 & 262 & 0 & 48 & 250 \\
\hline Gharib et $a l^{13}$ & Egypt & PB & PCR-RFLP & 0.58 & $120 / 100$ & 4 & 30 & 86 & 6 & 39 & 85 \\
\hline He et $a l^{18}$ & China & PB & PCR-RFLP & 0.59 & $300 / 300$ & 10 & 67 & 223 & 2 & 37 & 261 \\
\hline $\mathrm{Li}$ and Meng ${ }^{14}$ & China & $\mathrm{HB}$ & PCR-RFLP & 0.60 & $178 / 196$ & 0 & 26 & 152 & 0 & 14 & 182 \\
\hline Xu et $a l^{17}$ & China & PB & PCR-RFLP & 0.58 & $270 / 540$ & 0 & 37 & 233 & 0 & 25 & 515 \\
\hline
\end{tabular}

HB, hospital-based; PB, population-based; PCR-RFLP, PCR-restriction fragment length polymorphism; $P_{\text {HWE, Hardy-Weinberg equilibrium of }}$ controls. 
Table 4 Main characteristics of studies of cyclo-oxygenase-2 T+8473C polymorphism and the risk of hepatocellular carcinoma

\begin{tabular}{|c|c|c|c|c|c|c|c|c|c|c|c|}
\hline \multirow[b]{2}{*}{ Study } & \multirow[b]{2}{*}{ Country } & \multirow{2}{*}{$\begin{array}{l}\text { Source of } \\
\text { control }\end{array}$} & \multirow{2}{*}{$\begin{array}{l}\text { Genotyping } \\
\text { method }\end{array}$} & \multirow[b]{2}{*}{$\mathbf{P}_{\text {HWE }}$} & \multirow{2}{*}{$\begin{array}{l}\text { Cases/ } \\
\text { controls }\end{array}$} & \multicolumn{3}{|c|}{ No. of cases } & \multicolumn{3}{|c|}{ No. of controls } \\
\hline & & & & & & $\overline{C C}$ & TC & TT & $\overline{C C}$ & TC & TT \\
\hline Akkiz et $a l^{10}$ & Turkey & $\mathrm{HB}$ & PCR-RFLP & 0.16 & $129 / 129$ & 8 & 56 & 65 & 9 & 62 & 58 \\
\hline Chang et al ${ }^{11}$ & Taiwan & PB & PCR-RFLP & $<0.001$ & $298 / 298$ & 0 & 103 & 195 & 0 & 97 & 201 \\
\hline Fan et $a l^{12}$ & China & $\mathrm{HB}$ & $\begin{array}{l}\text { TaqMan genotyping } \\
\text { platform }\end{array}$ & 0.22 & $780 / 780$ & 36 & 235 & 509 & 25 & 258 & 497 \\
\hline
\end{tabular}

HB, hospital-based; PB, population-based; PCR-RFLP, PCR-restriction fragment length polymorphism; $P_{\text {HWE, Hardy-Weinberg equilibrium of }}$ controls.

Chinese population. However, we did not find compelling evidence of an association between other COX-2 gene polymorphisms and the risk of HCC development.

As is known, the polymorphisms in the COX-2 promoter may have an important effect on gene transcriptional activity by changing the binding capacity of certain nuclear proteins, thereby affecting COX-2 expression. Even though the exact molecular mechanism still remains unclear, several polymorphisms of COX-2 have been published previously and the results are still conflicting. A previous meta-analysis of eight studies showed that the COX-2 C+202T polymorphism is associated with a lower risk of prostate cancer in Caucasians. ${ }^{26}$ Another meta-analysis of 25 studies found that the COX-2 A-1195G polymorphism is a low penetrance risk factor for cancer. ${ }^{27}$ However, COX-2 C-765G and $\mathrm{T}+8473 \mathrm{C}$ polymorphisms are significantly associated with an increased risk of digestive system cancers. ${ }^{28} 29$ The meta-analysis by $\mathrm{Bu}$ and $\mathrm{Zhao}^{30}$ included five ${ }^{10-12}$ 1517 of the 10 studies included in our review. They found an association between COX-2 A-1195G polymorphism and the risk of HCC development, especially in Asians.

In our updated review, with a larger sample size, another five studiess ${ }^{13} \quad 14 \quad 16 \quad 18 \quad 19$ were included. We found that the GG genotype at the A-1195G polymorphism was associated with a reduced risk of HCC development across all studies. We also investigated another seven polymorphic variants (G-765C, T+8473C, intron 1, intron 5, intron 6, A-1290G, C-899G) of COX-2. Although COX-2 C-899G polymorphism may increase the risk of HCC, this result was based on only one study. In order to demonstrate the association between the COX-2 C-899G polymorphism and risk of HCC development, more reliable data with a large sample size are needed.

Development of HCC is a complex, multistep and heterogeneous malignant tumorigenesis process. The aetiology of HCC involves various host and environmental factors. Furthermore, host and environmental factors may interact synergistically in HCC pathogenesis and progression. ${ }^{4}$ Several studies in this review indicate that COX-2 polymorphisms can interact with environmental factors to modulate the HCC risk. Among people with a history of drinking, COX-2-765 C allele carriers lead to a significantly greater risk of HCC development than the $\mathrm{G}$ allele. ${ }^{18} 31$ Though single gene polymorphism and risk of HCC development was not found in the study by Fan $e t a l,{ }^{12}$ demographic interactions were seen. Among people aged $<55$ years, the A allele of the COX-2 A-1195G polymorphism is a high penetrance risk factor for HCC development, whereas among women, the $\mathrm{C}$ allele of COX-2 $\mathrm{T}+8473 \mathrm{C}$ is a low penetrance risk factor for HCC. For gene-gene interactions, no significant



Figure 2 Forest plots describing the association of A-1195G COX-2 polymorphism with hepatocellular carcinoma (GG vs GA $+A A)$. 


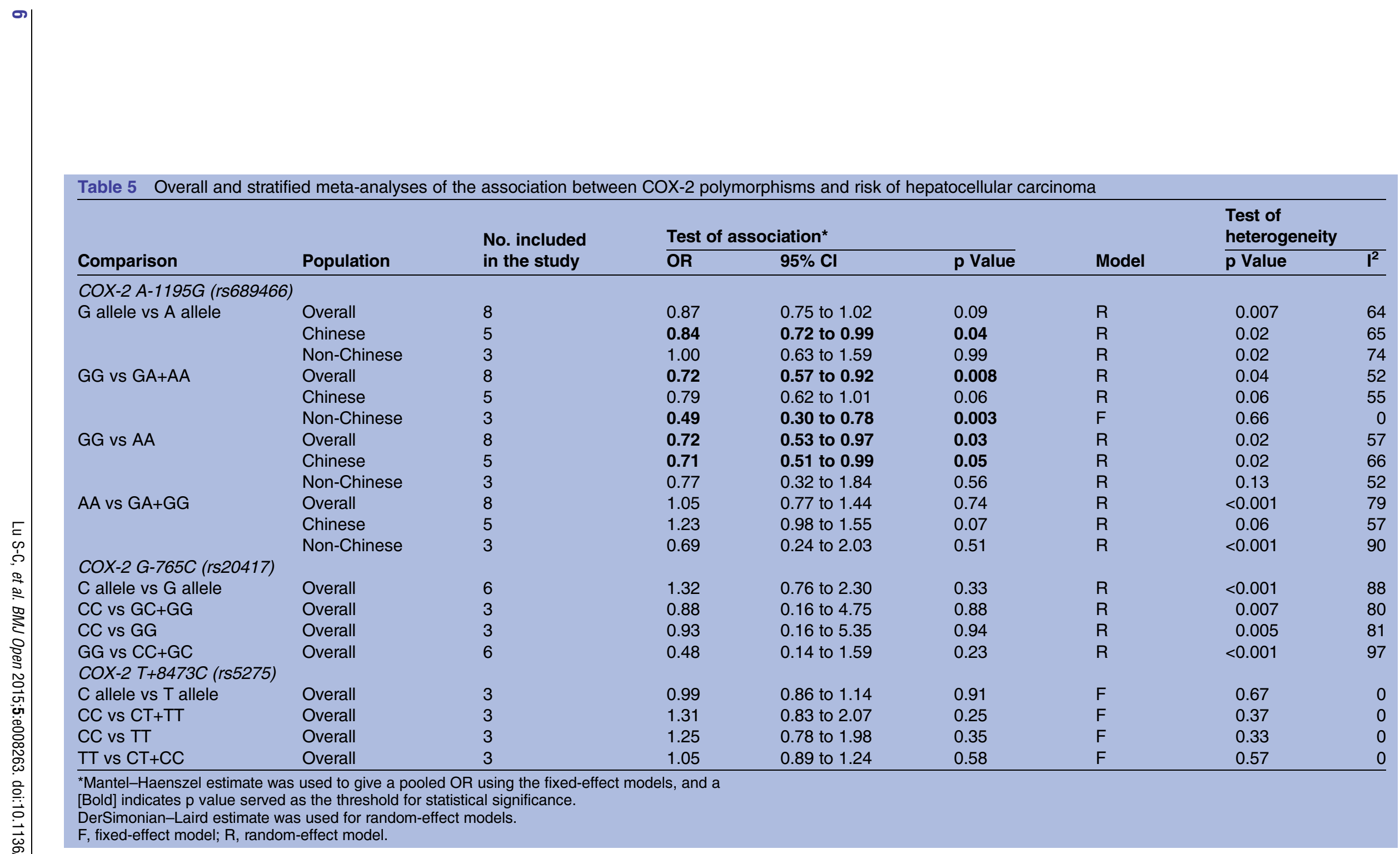


Table 6 Ethnicity meta-regression and publication bias of COX-2 A-1195G polymorphisms and risk of hepatocellular carcinoma

\begin{tabular}{lcccll}
\hline Variables & Coefficient & $\mathbf{S E}$ & $\mathbf{z}$ & $\mathbf{p ~ V a l u e}$ & $\mathbf{9 5 \%} \mathbf{C l}$ \\
\hline Meta-regression & & & & & \\
G allele vs A allele & -0.107 & 0.271 & -0.40 & 0.693 & -0.639 to 0.424 \\
GG vs GA+AA & 0.520 & 0.435 & 1.20 & 0.232 & -0.3321 to 1.373 \\
GG vs AA & 0.217 & 0.574 & 0.38 & 0.706 & -0.909 to 1.342 \\
AA vs GA+GG & 0.282 & 0.561 & 0.50 & 0.616 & -0.819 to 1.382 \\
$\begin{array}{l}\text { Publication bias by Egger's test } \\
\text { G allele vs A allele }\end{array}$ & -0.059 & & & & \\
GG vs GA+AA & 0.148 & 0.210 & -0.28 & 0.788 & -0.573 to 0.455 \\
GG vs AA & -0.017 & 0.196 & 0.75 & 0.481 & -0.3332 to 0.628 \\
AA vs GA+GG & 0.416 & 0.323 & -0.05 & 0.959 & -0.807 to 0.772 \\
\hline
\end{tabular}

difference in the frequencies of any combined genotypes was seen between patients with HCC and healthy controls. ${ }^{11}$ Additionally, no combined effects of COX-2 genotypes and smoking or alcohol drinking were found. ${ }^{11}$ Moreover, no significant difference in COX-2 C-899G genotype distribution interactions with age, sex or smoking history was found. ${ }^{19}$ Therefore, whether the gene-gene and gene-environment interactions of the COX-2 polymorphism may contribute to the risk of HCC is unknown.

Our data showed that COX-2 A-1195G gene polymorphism may be a protective factor for hepatocarcinogenesis, but the complete picture is more complex. Seven ${ }^{11} 121415$ 17-19 of the 10 studies included Chinese people. China has among the highest incidence of HCC in the world, as well as a high prevalence of hepatitis B virus infection and dietary exposure to aflatoxin B1, which are the two main risk factors for HCC. ${ }^{32-34}$ Some of the included controls had hepatitis B or C virus infection, or cirrhosis. Because the sample size of these controls is small, a subgroup analysis based on a liver disease background was not performed. In addition, polymorphisms in numerous other genes, such as those encoding microsomal epoxide hydrolase ${ }^{4}$ and epidermal growth factor ${ }^{5}$ are associated with the risk of HCC. It may be that any single nucleotide polymorphism such as COX-2 A-1195G or epidermal growth factor $61^{*} \mathrm{~A} / \mathrm{G}$ is insufficient on its own to cause HCC.

As mentioned, some of the controls had one or more of the following: alcoholic liver disease, hepatitis B or C virus infection and cirrhosis. Since the studies included in this review often did not report detailed statistics on the proportion of patients with HCC or control subjects with these background conditions, we could not perform a subgroup analysis to separate the contribution of COX-2 polymorphism from that of possible confounders like hepatitis B or $\mathrm{C}$ infection. In addition, it is hard to assess the quality of the included studies, which may also lead to bias.

Low occurrence of genotypes within the COX-2 G-765C and COX-2 T+8473C polymorphisms may lead to null results in table 5 . Therefore, more reliable data with larger sample sizes are needed to determine the relationships involving COX-2 G-765C and COX-2 $\mathrm{T}+8473 \mathrm{C}$ polymorphisms, whose analyses have been underpowered and whose null results must be treated with caution.

Some other limitations of this review should also be considered. Although we searched all the eligible records, the number of studies included was still relatively small. Subgroup stratification analysis of other COX-2 gene polymorphisms was not performed. Moreover, meta-analysis was not carried out for five polymorphic variants of COX-2. Second, the results may be affected by additional confounding factors, such as tumour status, age or gender, but most studies either did not report these baseline data or aggregated them in different ways, making it impossible to include them into the pooled analysis. Moreover, the distribution of genotypes among controls did not show HWE in several studies. Finally, because of the lack of the individual original data, our meta-analysis was based on unadjusted data, and a more precise analysis stratified by clinical manifestation and environmental factors was not performed.

In conclusion, this review suggests that the COX-2 A-1195G gene polymorphism, rather than the other seven polymorphic variants of COX-2, might be a protective factor against HCC development. However, since this review included few studies, large, well-designed studies are warranted to re-evaluate these associations.

Contributors S-CL conceived and designed the experiments; S-CL, J-TT, H-LT and $\mathrm{J}-\mathrm{HZ}$ performed the research; B-DX, L-QL and X-GL performed the statistical analysis; S-CL and J-HZ wrote the manuscript; all authors read and approved the final manuscript.

Funding This work was supported by grants in part by the National Nature Science Foundation of China (NSFC 81560535, 81072321, 30760243, 30460143 and 30560133), 2009 Program for New Century Excellent Talents in University, Guangxi Nature Sciences Grant (GuiKeGong 1104003A-7), Guangxi Health Ministry Medicine Grant (Key-Scientific-Research-Grant Z201018), the Innovation Project of Guangxi Graduate Education (YCBZ2015030), grants from Programs for Changjiang Scholars and Innovative Research Team in University (No.IRT1119), and Innovative Research Team in Guangxi Natural Science Foundation (No.2011GXNSFF018005). 
Competing interests None declared.

Provenance and peer review Not commissioned; externally peer reviewed.

Data sharing statement No additional data are available.

Open Access This is an Open Access article distributed in accordance with the Creative Commons Attribution Non Commercial (CC BY-NC 4.0) license, which permits others to distribute, remix, adapt, build upon this work noncommercially, and license their derivative works on different terms, provided the original work is properly cited and the use is non-commercial. See: http:// creativecommons.org/licenses/by-nc/4.0/

\section{REFERENCES}

1. Siegel R, Ma J, Zou Z, et al. Cancer statistics, 2014. CA Cancer J Clin 2014;64:9-29.

2. Zhang $\mathrm{CY}$, Huang TR, Yu JH, et al. Epidemiological analysis of primary liver cancer in the early 21 st century in Guangxi province of China. Chin J Cancer 2010;29:545-50.

3. Zhong JH, Ke Y, Gong WF, et al. Hepatic resection associated with good survival for selected patients with intermediate and advanced-stage hepatocellular carcinoma. Ann Surg 2014;260:329-40.

4. Zhong JH, Xiang BD, Ma L, et al. Meta-analysis of microsomal epoxide hydrolase gene polymorphism and risk of hepatocellular carcinoma. PLoS One 2013:8:e57064.

5. Zhong JH, You XM, Gong WF, et al. Epidermal growth factor gene polymorphism and risk of hepatocellular carcinoma: a meta-analysis. PLoS One 2012;7:e32159.

6. Williams CS, Mann M, DuBois RN. The role of cyclooxygenases in inflammation, cancer and development. Oncogene 1999;18:7908-16.

7. Trifan OC, Hla T. Cyclooxygenase-2 modulates cellular growth and promotes tumorigenesis. J Cell Mol Med 2003;7:207-22.

8. Bae SH, Jung ES, Park YM, et al. Expression of cyclooxygenase-2 (COX-2) in hepatocellular carcinoma and growth inhibition of hepatoma cell lines by a COX-2 inhibitor, NS-398. Clin Cancer Res 2001;7:1410-18.

9. Sung YK, Hwang SY, Kim JO, et al. The correlation between cyclooxygenase-2 expression and hepatocellular carcinogenesis. Mol Cells 2004;17:35-8.

10. Akkiz H, Bayram S, Bekar A, et al. Functional polymorphisms of cyclooxygenase-2 gene and risk for hepatocellular carcinoma. $\mathrm{Mol}$ Cell Biochem 2011;347:201-8.

11. Chang WS, Yang MD, Tsai CW, et al. Association of cyclooxygenase 2 single-nucleotide polymorphisms and hepatocellular carcinoma in Taiwan. Chin J Physiol 2012;55:1-7.

12. Fan XJ, Qiu XQ, Yu HP, et al. Association of COX-2 gene SNPs with the risk of hepatocellular carcinoma (in Chinese). Chin $J$ Cancer Prev Treat 2011;18:405-9.

13. Gharib AF, Karam RA, Abd El Rahman TM, et al. COX-2 polymorphisms $-765 \mathrm{G} \rightarrow \mathrm{C}$ and $-1195 \mathrm{~A} \rightarrow \mathrm{G}$ and hepatocellular carcinoma risk. Gene 2014:543:234-6.

14. Li YH, Meng W. The Association of Survivin and COX-2 Gene with Hepatocellular Carcinoma. Master Dissertation. Fudan University, 2011.

15. Liu LF, Zhang JL, Lin JS. The relationship between cyclooxygenase-2 gene $-1195 \mathrm{G} / \mathrm{A}$ genotype and risk of
HBV-induced HCC: a case-control study in Han Chinese people (in Chinese). Chin J Gastroenterol Hepatol 2010;19:333-5.

16. Mohamed FZ, Hussein YM, El-Deen IM, et al. Cyclooxygenase-2 single-nucleotide polymorphisms and hepatocellular carcinoma in Egypt. Mol Biol Rep 2014;41:1461-8.

17. Xu DK, Zhang XM, Zhao $P$, et al. Association between single nucleotide polymorphisms in promoter of COX-2 gene and hereditary susceptibility to hepatocellular carcinoma (in Chinese). Chin J Hepatobiliary Surg 2008;14:587-9.

18. He J, Zhang Q, Ren Z, et al. Cyclooxygenase-2 -765 G/C polymorphisms and susceptibility to hepatitis B-related liver cancer in Han Chinese population. Mol Biol Rep 2012;39:4163-8.

19. $\mathrm{He} \mathrm{JH}$, Li YM, Zhang QB, et al. Cyclooxygenase-2 promoter polymorphism -899G/C is associated with hepatitis B-related liver cancer in a Chinese population of Gansu province. Chin Med J (Engl) 2011;124:4193-7.

20. Zhong JH, Rodríguez AC, Yang NN, et al. Methylenetetrahydrofolate reductase gene polymorphism and risk of type 2 diabetes mellitus. PLoS One 2013;8:e74521.

21. Zhong JH, Zhang ZM, Li LQ. mEH Tyr113His polymorphism and the risk of ovarian cancer development. J Ovarian Res 2013;6:40.

22. Higgins JP, Thompson SG, Deeks JJ, et al. Measuring inconsistency in meta-analyses. BMJ 2003;327:557-60.

23. Higgins JP, Thompson SG. Quantifying heterogeneity in a meta-analysis. Stat Med 2002;21:1539-58.

24. Liberati A, Altman DG, Tetzlaff J, et al. The PRISMA statement for reporting systematic reviews and meta-analyses of studies that evaluate health care interventions: explanation and elaboration. PLoS Med 2009;6:e1000100.

25. Egger M, Davey Smith G, Schneider M, et al. Bias in meta-analysis detected by a simple, graphical test. BMJ 1997;315:629-34.

26. Zhang $\mathrm{H}, \mathrm{Xu} \mathrm{Y}$, Zhang Z, et al. Association between COX-2 rs2745557 polymorphism and prostate cancer risk: a systematic review and meta-analysis. BMC Immunol 2012;13:14.

27. Tang Z, Nie ZL, Pan Y, et al. The Cox-2-1195 G>A polymorphism and cancer risk: a meta-analysis of 25 case-control studies. Mutagenesis 2011;26:729-34.

28. Dong J, Dai J, Zhang M, et al. Potentially functional COX-2$1195 \mathrm{G}>\mathrm{A}$ polymorphism increases the risk of digestive system cancers: a meta-analysis. J Gastroenterol Hepatol 2010;25:1042-50.

29. Wang XF, Huang MZ, Zhang XW, et al. COX-2-765G $>C$ polymorphism increases the risk of cancer: a meta-analysis. PLoS One 2013;8:e73213.

30. Bu X, Zhao C. The association between cyclooxygenase-2 1195 G/A polymorphism and hepatocellular carcinoma: evidence from a meta-analysis. Tumour Biol 2013;34:1479-84.

31. Song X, Cheng SH, Liu C, et al. Cyclooxygenase-2 polymorphism and susceptibility to hepatocellular carcinoma. Practic $J$ Cancer 2011;26:255-8.

32. Wang FS, Fan JG, Zhang Z, et al. The global burden of liver disease: The major impact of China. Hepatology 2014;60:2099-108.

33. Zhong JH, Zhong QL, Li LQ, et al. Adjuvant and chemopreventive therapies for resectable hepatocellular carcinoma: a literature review. Tumour Biol 2014;35:9459-68.

34. Zhong JH, Rodríguez AC, Ke Y, et al. Hepatic resection as a safe and effective treatment for hepatocellular carcinoma involving a single large tumor, multiple tumors, or macrovascular invasion. Medicine (Baltimore) 2015;94:e396. 